\title{
PENGEMBANGAN TEKNIK PEMBELAJARAN PASSING DADA PADA PERMAINAN BOLA BASKET SISWA KELAS VIII SMP
}

\author{
Reza Resah Pratama ${ }^{1)}$ dan Marsiyem ${ }^{2)}$ \\ ${ }^{1,2}$ Pendidikan Jasmani dan Kesehatan, Fakultas Keguruan dan Ilmu Pendidikan, Universitas Sriwijaya \\ ${ }^{1,2}$ Jalan Palembang-Prabumulih, Km 32 Inderalaya, kabupaten Ogan Ilir, 30662 \\ E-mail: rezaresah@fkip.unsri.ac.id ${ }^{1)}$, marsiyem@ @kipunsri.ac.id ${ }^{2}$ )
}

\begin{abstract}
ABSTRAK
Penelitian ini bertujuan untuk mengembangkan teknik pembelajaran passing dada pada permainan bola basket untuk siswa SMP kelas VIII sebagai solusi bagi guru untuk meningkatkan hasil belajar peserta didik. Pengembangan teknik pembelajaran passing dada dilakukan di SMP Negeri 1 Palembang dengan menggunakan metode penelitian research and development. Subjek dalam penelitian ini adalah siswa SMP N 1 Palembang Kelas VIII sebanyak 30orang. Langkah langkah pengembangan yang digunakan adalah Potensi dan masalah, (2) Desain produk, (3) Validasi Produk (4) Ujicoba Pemakaian, (5) Revisi Produk, (6) Ujicoba Produk, (7) Produk akhir. Berdasarkan validasi ahli produk pengembangan ini dikatakan layak, sehingga dilakukan ujiefektifitas produk. Hasil ujiefektifitas dengan menggunakan metode eksperimen diketahui bahwa nilai rata-rata passing dada dalam kelompok eksperimen dilakukan pada 30 siswa didapatkan hasil 18,57 sedangkan nilai rata-rata passing dada kelompok kontrol adalah 14,77 artinya terdapat perbedaan dan nilai rata-rata kelompok eksperimen lebih tinggi dari nilai rata-rata kelompok kontrol. Pada uji signifikan perbedaan t-hitung $=7,477$, df $=58$ dan $\mathrm{p}$-value $=0,00<0,05$ berarti terdapat perbedaan signifikan antara hasil passing dada kelompok eksperimen dan hasil kelompok kontrol. Hasil ujiefektifitas meunjukan bahwa pengembangan teknik pembelajaran passing dada pada permainan bola basket efektif dan efisien. Pengembangan teknik pembelajaran passing dada ini dapat meningkatkan variasi teknik pembelajaran guru Pendidikan Jasmani Olahraga dan Kesehatan sehingga meningkatkan prestasi siswa.
\end{abstract}

\section{Kata kunci: Pengembangan Pembelajaran, Pasing Dada, Permainan Bolabasket.}

\section{PENDAHULUAN}

Peningkatan kualitas pendidikan sekarang ini merupakan kebutuhan yang mendesak, mengingat kualitas pendidikan di Indonesia sudah tertinggal jauh dari negara tetangga apalagi jika dibandingkan dengan negara maju. Permasalahan yang mendasar dalam dunia pendidikan di Indonesia adalah masalah kualitas, kuantitas dan relevansi. Kualitas dari pendidikan itu sendiri tentunya tidak dapat lepas dari proses dan hasil belajar. Proses pendidikan menentukan hasil belajar oleh karena itu proses pendidikan harus dirancang dengan baik agar mampu menikngkatkan hasil belajar yang maksimal yang sesuai dengan kebutuhan siswa. Hasil belajar yang demikian adalah hasil belajar yang memiliki dimensi jangka panjang yang dapat membekali siswa dalam kehidupan dan belajar sepanjang hayatyaitu kemampuan berfikir, kecakapan hidup, psikomotor, dan tentunya hasil belajar itu sendiri.

Sekolah adalah sebagai lembaga formal dalam sistem pendidikan tidak terlepas dari usaha-usaha peningkatan prestasi belajar anak didik. Kegiatan proses pembelajaran merupakan kegiatan pokok dalam kesuluruhan kegiatan pendidikan disekolah. Hal ini berarti berhasil tidaknya pencapaian tujuan pendidikan dalam bentuk terjadinya perubahan tingkah laku, pengetahuan, maupun keterampilan siswa tergantung pada bagaimana proses pembelajaran yang dialami oleh siswa sebagai peserta didik.

Pendidikan Jasmani pada dasarnya merupakan bagian integral dari sistem pendidikan secara keseluruhan bertujuan untuk mengembangkan aspek kesehatan, kebugaran jasmani, keterampilan berfikir kritis, stabilitas emosional, keterampilan sosial, penalaran dan tindakan moral melalui aktivitas jasmani dan olahraga. Pendidikan jasmani adalah proses belajar, bergerak, dan belajar melalui gerak (Mulyanto, 2014)

Kenyataan bahwa kondisi pendidikan jasmani nasional yang belum ideal seperti di atas, untuk itu diperlukan kebijakan dan langkah pengembangan sampai di tingkat satuan pendidikan secara nyata, efektif dan konsisten. Salah satu terobosan yang dapat dilakukan adalah dengan membuat model pembelajaran yang unggul dan memungkinkan diterapkan di sebagian besar satuan pendidikan nasional. Pendidikan jasmani yang dirancang dan dilaksanakan dengan strategi dan proses pembelajaran yang benar akan mampu berperan dan memberikan kontribusi yang bermakna dalam pembentukan watak dan kepribadian siswa.

Masih banyaknya jumlah sekolah-sekolah yang tidak memiliki fasilitas pendidikan jasmani yang layak dan memadai bahkan seringkali harus mencari lahan kosong, bergantian atau bahkan berdesak-desakan dengan beberapa sekolah lain untuk bisa menggunakan lahan yang 
ada. Kendala kurang lancarnya pembelajaran pendidikan jasmani di sekolah-sekolah adalah kurang memadainya sarana yang dimiliki oleh sekolah-sekolah tersebut. Di samping itu ketergantungan para guru penjas pada sarana yang standar serta pendekatan pembelajaran pada penyajian teknik-teknik dasar juga standar sesuai dengan kurikulum yang ditetapkan. Kedua hal tersebut menyebabkan pola pembelajaran yang kurang variatif dan cenderung membosankan bagi peserta didik.

Guru Pendidikan Jasmani Olahraga dan Kesehatan sebenarnya dapat berbuat banyak dan lebih leluasa dalam menggunakan, memanfaatkan, mengembangkan atau bahkan memodifikasi sarana yang akan digunakan. Pengembangan teknik pembelajaran merupakan salah satu upaya meningkatkan kualitas pembelajaran siswa. Penelitian di bawah ini adalah penelitian terdahulu yang telah dilakukan dalam peningkatan hasil belajar siswa yaitu Bazuri Fadila Amin (2018) dalam penelitiannya menyimpulakan bahwa pembelajaran operan dada (chest pass) dalam permainan basket melalui metode mengajar penemuan terpimpin dapat meningkatkan kemampuan chest pass dengan hasil $83 \%$ siswa dapat melakukan chest passing bola basket.

Mohammad, Y., Sutardji, dan Taufik, H (2012) hasil penelitian ini menunjukkan adanya sumbangan yang signifikan power lengan, panjang lengan, terhadap kemampuan lemparan chest pass pada pemain bola basket, selain itu pada penelitian Anugerah, B., Oni B., \& Usman, W (2016). Hasil penelitian dan pengembangan model latihan kombinasi dribbling, passing dan shooting ini layak dan dapat digunakan untuk peserta ekstrakurikuler bolabasket.

Penelitian-penelitian sebelumnya belum ada yang mengembangkan teknik pembelajaran chest pass, maka penelitian ini akan mengembangkan teknik pembelajaran passing dada pada permainan basket yang diperuntukkan untuk siswa SMP kelas VIII.

Pengembangan ini diharapkan menghasilkan temuan terbaru berupa teknik pembelajaran passing dada dalam permainan bola baket pada siswa SMP kelas VIII berupa buku panduan pembelajaran.

\section{RUANG LINGKUP}

Permasalahan pada penelitian ini tentang minimnya variasi teknik pembelajaran passing dada dalam permainan bola basket pada siswa kelas VIII SMP. Adapun batasan masalah adalah sebatas pada bagaimana mengembangkan teknik pembelajaran passing dada permainan bola basket untuk siswa SMP kelas VIII . Apakah pengembangan teknik pembelajaran passing dada bola basket layak dan efektif digunakan bagi siswa SMP kelas VIII. Penelitian ini diharapkan memberikan kontribusi dalam menambah variasi teknik pembelajaran khususnya pembelajaran bola basket SMP kelas VIII. Pengembangan ini menghasilkan teknik pembelajaran berupa buku panduan pembelajaran bola basket dengan materi passing dada, sehingga dengan dihasilkan buku panduan ini dapat menambah referensi bahan ajar bagi Guru Pendidikan Jasmani, Olahraga dan Kesehatan.

\section{BAHAN DAN METODE}

Menurut Hamzah B. Uno (2011), teknik pembelajaran adalah jalan, alat, atau media yang digunakan guru untuk mengarahkan kegiatan siswa ke tujuan yang diinginkan atau dicapai. Permainan Bola basket "Basketball is an open-skill team sport, strongly depending on the players capability to move quickly (Cortis dkk, 2011)". Christos Galazoulas (2017) menyatakan "bolabasket adalah olahraga tim yang dinamis, yang merupakan olahraga populer di dunia, laki-laki dan perempuan terlibat dalam pelatihan bolabasket pada keseluruhan harus mengembangkan keterampilan motorik pada level tinggi, seperti tipuan tiba-tiba, berhenti, berlari, melompat, kelincahan dan fleksibilitas" Barth \& Boesing (2010) bola basket adalah olahraga yang terdiri dari dua tim, bola, dua ring, terdapat banyak kesempatan untuk saling menyerang, berfikir cepat dan tentunya menyenangkan.

Prosedur pengembangan yang digunakan dalam penelitian ini mengunakan metode research and Development (R\&D). Menurut (Sugiyono, 2013) metode penelitian pengembangan adalah metode penelitian yang digunakan untuk menghasilkan produk tertentu, dan mengkaji keefektifan produk tersebut. Penelitian pengembangan ini dilaksanankan di SMP N 1Palembang Kelas VIII semester 1 tahun ajaran 2018/2019. Langkahlangkah pengembangan penelitian dan pengembangan menurut Sugiyono, adalah penelitian yang digunakan untuk menghasilkan produk tertentu, dan menguji keefektifan produk tersebut. Research \& Development $(R$ $\& D)$ menurut Sugiyono (2013) terdiri dari sepuluh langkah dan dimodifikasi menjadi 7 langkah yakni:

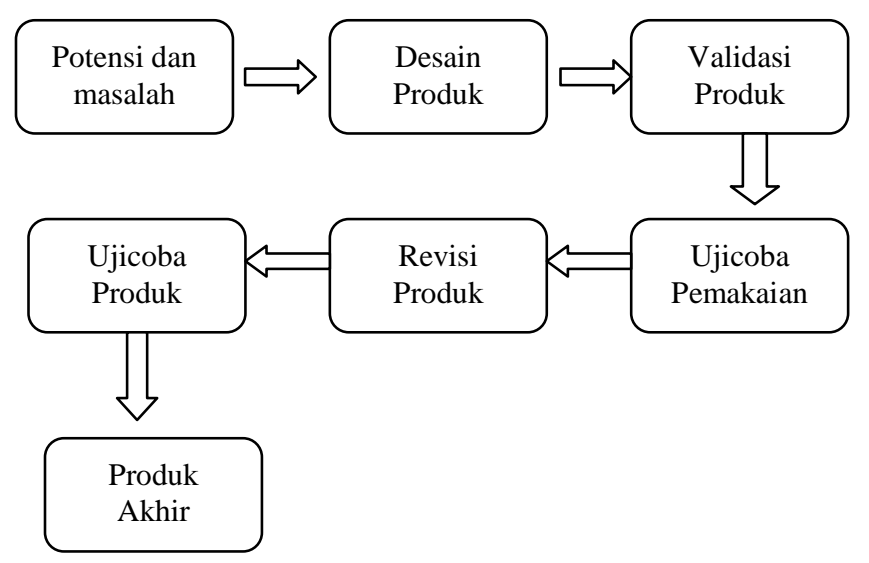

Gambar 1. Prosedur Pengembangan Penelitian Teknik Pembelajaran Passing Dada

\section{PEMBAHASAN}


Pada penelitian pengembangan teknik pembelajaran passing dada SMP kelas VIII ini akan dibahas hasil penelitian.

\subsection{Potensi dan Masalah}

Teknik latihan keterampilan passing dada dalam permainan bola basket yang akan dikembangkan merupakan hasil dari permasalahan yang ditemukan oleh peneliti dilapangan melalui obeservasi dan wawancara terhadap guru olahraga di sekolah. Berdasarkan observasi dan wawancara yang dilakukan oleh peneliti maka diperoleh tujuan umum dari pengembangan teknik latihan keterampilan passing dada dalam permainan bola basket untuk siawa, disamping beberapa tujuan umum peneliti juga dapat mengetahui beberapa kharakteristik subjek dari teknik keterampilan passing dada yang akan dikembangkan.

\subsection{Desain Produk}

Desain produk dilakukan dengan membuat draf produk sesuai dengan indikator yang telah dibuat, yang akan diuji kelayakannya oleh validasi ahli bola basket serta, dosen baket, serta guru pendidikan jasmani.

\subsubsection{Validasi Ahli}

Pada penelitian ini menggunakan 3 orang ahli dalam penilaian kelayakan teknik, teknik passing dada dalam permainan bola basket yang dibuat, dimana 3 orang ahli berprofesi sebagai Dosen Olahraga dan Guru permainan bola basket. Adapun kesimpulan dari uji ahli yang dilakukan terangkum dalam Tabel 1.

Tabel 1. Kesimpulan Uji Ahli Terhadap Teknik Keterampilan Passing Dada Permainan Bola Basket

\begin{tabular}{|c|c|c|c|}
\hline \multirow[t]{2}{*}{ No } & \multirow[t]{2}{*}{ Nama } & $\begin{array}{c}\text { Penerimaan } \\
\text { Teknik }\end{array}$ & \multirow[t]{2}{*}{ Keterangan } \\
\hline & & Ya Tidak & \\
\hline 1 & Teknik passing dada 1 & $\sqrt{ }$ & Layak/Valid \\
\hline 2 & Teknik passing dada 2 & $\sqrt{ }$ & Layak/Valid \\
\hline 3 & Teknik passing dada 3 & $\sqrt{ }$ & Layak/Valid \\
\hline 4 & Teknik passing dada 4 & $\sqrt{ }$ & Layak/Valid \\
\hline 5 & Teknik passing dada 5 & $\sqrt{ }$ & Layak/Valid \\
\hline
\end{tabular}

Berdasarkan pada Tabel 1. Maka Uji ahli yang dilakukan dapat ditarik kesimpulan bahwa teknik keterampilan pembelajaran passing dada permainan bola basket layak dan dapat digunakan dalam pembelajaran passing dada permainan bola basket.

\subsection{Ujicoba Pemakaian}

Ujicoba pemakaian $\mathrm{n}$ ini dilakukan pada kelompok kecil dan kelompok besar dengan tujuan menguji kelayakan produk. Adapun hasil dari ujicoba dijelaskan sebagai berikut:

1. Hasil Tahap Pertama/Ujicoba Kelompok Kecil

Teknik pembelajaran passing dada permainan bola basket yang peneliti buat setelah dievaluasi ahli, kemudian mengalami revisi tahap I. Data yang diperoleh digunakan sebagai landasan dalam melakukan revisi pada tahap pertama selanjutnya yaitu ujicoba tahap II. Berikut merupakan ringkasan revisi tahap pertama berdasarkan evaluasi dan saran dari para ahli.

Tabel 2. Hasil Revisi dari Ahli Terhadap Teknik Keterampilan Passing Dada Permainan Bola Basket

\begin{tabular}{|c|c|c|}
\hline No & $\begin{array}{l}\text { Teknik Passing } \\
\text { Dada }\end{array}$ & Saran dan Masukan \\
\hline 1 & Teknik 1 & $\begin{array}{l}\text { Teknik latihan ini cocok untuk } \\
\text { peserta didik }\end{array}$ \\
\hline 2 & Teknik 2 & $\begin{array}{l}\text { Teknik latihan ini cocok untuk } \\
\text { peserta didik }\end{array}$ \\
\hline 3 & Teknik 3 & $\begin{array}{l}\text { Teknik latihan ini cocok untuk } \\
\text { peserta didik }\end{array}$ \\
\hline 4 & Teknik 4 & $\begin{array}{l}\text { Teknik latihan ini cocok untuk } \\
\text { peserta didik }\end{array}$ \\
\hline 5 & Teknik 5 & $\begin{array}{l}\text { Teknik latihan ini cocok untuk } \\
\text { peserta didik }\end{array}$ \\
\hline
\end{tabular}

Berdasarkan Tabel 2. Pada evaluasi ujicoba kelompok kecil terdapat 5 teknik yang layak dari 5 bentuk teknik latihan yang telah diterapkan, berdasarkan uji ahli yang dilakukan tentang teknik latihan passing untuk atlet pemula dapat ditarik kesimpulan sebagai berikut: (1) Berdasarkan uji coba ahli yang dilakukan dapat disimpulkan bahwa item teknik 1,2,3,4,dan 5 merupakan teknik pembelajaran layak dilakukan olah siswa, melihat hasil ini bahwa sebuah pembelajaran yang dilakukan dengan modifikasi formasi valid digunakan adalah sesuai dengan penelitian Gede dkk (2014) yang mendapatkan hasil berupa (1) pelatihan passing formasi segitiga berpengaruh terhadap keterampilan passing (chest pass), (2) pelatihan passing formasi dalam lingkaran berpengaruh terhadap keterampilan passing (chest pass), (3) ada perbedaan pengaruh antara passing formasi segitiga dan formasi dalam lingkaran dimana passing formasi segitiga lebih baik dari pada passing formasi dalam lingkaran pada siswa peserta ekstrakulikuler bola basket SMP Negeri 2 Singaraja tahun 2014.

Berdasarkan evaluasi ujicoba kelompok kecil yang dilakukan oleh peneliti dapat disimpulkan sebagai berikut:

1) Semua teknik latihan dapat dilakukan dan diterapkan, akan tetapi harus disesuaikan dari tingkatan yang mudah ke yang sulit agar kemampuan passing dada siswa dapat meningkat.

2) Pada saat melakukan pembelajaran passing dada permainan bola basket atlet atau siswa cenderung terlalu terburu-buru dalam melakukan lemparan, dan juga dan juga menggunakan tenaga yang berlebihan, maka guru harus memberikan arahan agar anak melakukan tugasnya dengan benar agar timing yang diinginkan sesuai dengan hasil yang diharapkan

\section{Hasil Tahap Kedua/Ujicoba Kelompok Besar}


Hasil pengembangan produk teknik pembelajaran passing dada permainan bola basket ini diujicobakan dalam skala besar dan telah direvisi, maka tahap selanjutnya adalah melakukan ujicoba produk. Berdasarkan hasil ujicoba skala besar yang telah validasi oleh para ahli, kemudian melakukan revisi produk awal dan memperoleh 5 teknik, teknik pembelajaran passing dada permainan bola basket yang akan digunakan dalam ujicoba produk.

Menurut hasil penelitian Edo Harinda Setiawan (2017) ada pengaruh yang signifikan pembelajaran teknik terhadap hasil belajar passing chest pass bola basket dengan nilai thitung $8,741>$ nilai $\mathrm{t}$ table 1,7402 .

\subsection{Ujicoba Produk}

Ujicoba produk dilakuakn untuk melihat efektifitas produk dengan menggunakan subyek penelitian sebanyak 30 siswa Sekolah Menengah pertama yang terdiri dari 3 sekolah SMP N 1 palembang, SMP N 3 Palembang, dan SMP N 46 Palembang. Ujiefektifitas ini dilakukan dengan menggunakan metode ekperimen.

Hasil Akhir Perbandingan Passing dada Kelompok Eksperimen dan Kelompok Kontrol. Data penilaian dari 30 siswa terhadap efektivitas latihan latihan passing dada dalam kelompok eksperimen dan 30 siswa terhadap efektivitas latihan passing dada. Diagram di bawah ini adalah perbandingan rata-rata hasil passing dada dalam kelompok eksperimen dan rata-rata hasil passing dada dalam kelompok kontrol dalam bentuk diagram batang.

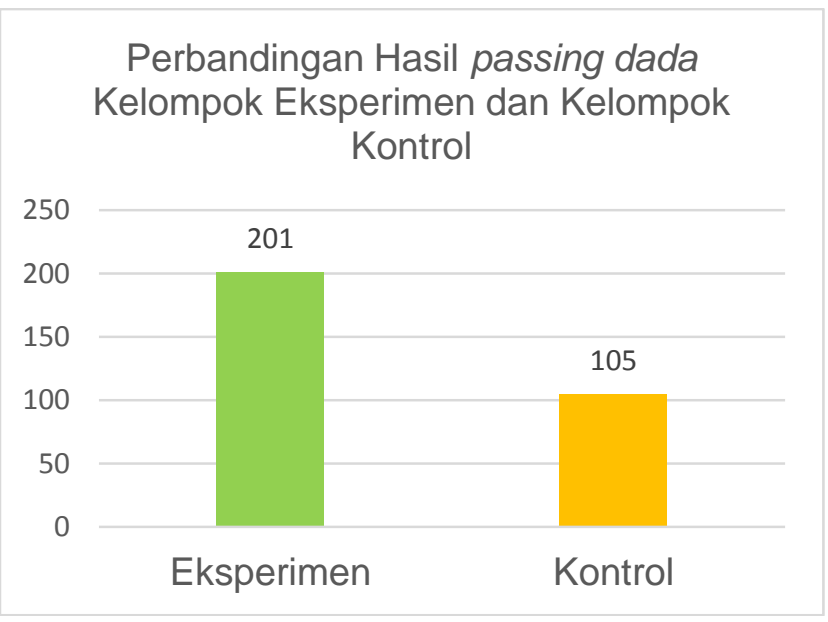

\section{Gambar 2. Diagram Batang Hasil passing dada Kelompok Eksperimen dan Kelompok Kontrol}

Berdasarkan Gambar 2. diperoleh data bahwa teknik pembelajaran passing dada permainan bola basket yang diberikan dalam kelompok eksperimen dengan hasil 201 belajar dan pada kelompok kontrol mendapat hasil belajar 105, hal ini menunjukkan bahwa kelompok yang dikenakan perlakuan lebih baik dari pada yang tidak. Hal ini menunjukkan bahwa teknik basket yang dikembangkan dapat meningkatkan hasil belajar passing dada permainan bola basket.

Berdasarkan hasil output dengan mengunakan SPSS 16 dapat diketahui bahwa nilai rata-rata passing dada dalam kelompok eksperimen adalah 18,57 sedangkan nilai rata-rata passing dada kelompok kontrol adalah 14,77 artinya terdapat perbedaan dan nilai rata rata kelompok eksperimen lebih tinggi dari nilai rata-rata kelompok kontrol. Dalam uji signifikan perbedaan dengan SPSS 16 terdapat hasil t-hitung $=7,477$, df $=58$ dan p-value $=0,00<0,05$ yang berarti terdapat perbedaan yang signifikan antara hasil passing dada kelompok eksperimen dan hasil kelompok control. Sejalan dengan hasil peningkatan pembelajaran sama dengan Hadi (2015) pada analisis uji pengaruh didapat nilai thitung $>$ ttabel $=16,197>2,024$, artinya terdapat pengaruh permainan lempar tangkap bola terhadap chest pass basket pada siswa kelas VIII.

\section{KESIMPULAN}

Penelitian dan pengembangan teknik pembelajaran passing dada permainan bola basket pada SMP Kelas VIII SMP Negeri 1 Palembang menggunakan langkah langkah pengembangan yang digunakan adalah Potensi dan masalah, (2) Desain produk, (3) Validasi desain, (4) Ujicoba Pemakaian, (5) Revisi produk, (6) Uji coba produk, (7) Produk Akhir. Berdasarkan validasi ahli produk pengembangan ini dikatakan valid (layak), sehingga dilakukan ujiefektifitas produk. Hasil ujiefektifitas dengan menggunakan metode eksperimen diketahui bahwa nilai rata-rata passing dada dalam kelompok eksperimen adalah 18,57 sedangkan nilai ratarata passing dada kelompok kontrol adalah 14,77 artinya terdapat perbedaan dan nilai rata-rata kelompok eksperimen lebih tinggi dari nilai rata-rata kelompok kontrol. Pada uji signifikan perbedaan t-hitung $=7,477$, $\mathrm{df}=58$ dan $\mathrm{p}$-value $=0,00<0,05$ berarti terdapat perbedaan signifikan antara hasil passing dada kelompok eksperimen dan hasil kelompok kontrol. Hasil ujiefektifitas meunjukan bahwa pengembangan teknik pembelajaran passing dada pada permainan bola basket efektif dan efisien. Pengembangan teknik pembelajaran passing dada ini dapat meningkatkan variasi teknik pembelajaran guru PJOK sehingga meningkatkan prestasi siswa.

\section{SARAN}

Dengan adanya buku ini diharapkan bagi Guru Pendidikan Jasmani, Olahraga, dan Kesehatan dapat memiliki wawasan yang luas mengenai perkembangan teknik-teknik pembelajaran pada saat ini, khususnya pada teknik pembelajaran passing dada ini, dan yang diharapkan dapat diterapkan dalam pembelajaran passing dada dalam permainan bola basket sehingga membuat guru lebih kreatif dan inovatif dalam mengajar sehingga dapat meningkatkan hasil belajar peserta didik 


\section{DAFTAR PUSTAKA}

Anugerah, B., Oni B., \& Usman, W. 2016. Pengembangan Model Latihan Kombinasi Dribbling, Passing Dan Shooting Peserta Ekstrakurikuler Bolabasket Di Smp Negeri 2 Kota Malang. Jurnal Pendidikan Jasmani, 26(2), 351364.

Barth \& Boesing. 2010. Training basketball. Maidenhead: Mayer Sport (UK). Ltd.

Bazuri Fadila Amin. 2018. Pembelajaran Operan Dada dalam Permainan Basket melalui Metode Mengajar Penemuan Terpimpin. Jurnal Ilmiah Sport Coaching and Education, P(2), 61-66

Christos Galazoulas,dkk. 2017. Acute Effects Of Static and Dynamic Stretching on the Sprint and Countermovement Jump of Basketball Players. Greece

Cortis dkk. 2011. Inter-Limb Coordination, Strength, Jump, and Sprint Performances Following A Yputh Men't Basketball Game France.

Depdiknas .2003. Undang-undang RI No.20 tahun 2003.Tentang Sistem Pendidikan Nasional.

Edo Harinda Setyawan. 2017. Pengaruh Pembelajaran Teknis Dan Taktis Terhadap Hasil Belajar Passing Chest Pass Bola Basket Pada Siswa Putra Kelas VIII. Jurnal simki-Techsain Vol 01. No 03. Hal 19.

Gede, dkk. 2014. Pengaruh Pelatihan Passing Formasi Segitiga Dan Formasi Dalam Lingkaran Terhadap Keterampilan Passing (Chest Pass) Bola Basket Pada Siswa Putra Ekstrakulikuler Smp Negeri 2 Singaraja Tahun $2014 . \quad$ Jurnal Pendidikan dan Kepelatihan, pISSN:2599 e ISSN: 2614-6932. Vol 2 No 1.

Hadi. 2015. Pengaruh Lempar Tangkap Bola Terhadap Chest Pass Bola Basket Di Smp Negeri 19 Pontianak. Jurnal Pendidikan dan Pembelajaran, Vol 4 No 5.

Hamzah B. Uno. 2011. Teori Motivasi dan Pengukurannya: Analisis di Bidang Pendidikan. Jakarta: Bumi aksara.

Mohammad Y, Sutardji, dan Taufik, H. 2012. Sumbangan Power Lengan Dan Panjang Lengan Terhadap Kemampuan Lempar Chest Pass Bola Basket Pada Klub Bola Basket Bluesky Kabupaten Demak. Jurnal of Sport Sciences and Fitness, 1(2), 58-62.

Mulyanto. 2014. Belajar Dan Pembelajaran Penjas. Bandung: Alfabeta.

Sugiyono. 2013. Metode Penelitian Kuantitatif, Kualitatif, dan Kombinasi Edisi Keempat. Bandung: Alfabeta.

\section{UCAPAN TERIMA KASIH}

Terimah kasih kepada Rektor Universitas Sriwijaya yang telah memberikan dana hibah penelitian satek sehingga penelitian ini dapat terlaksana. Terima kasih kepada kepala sekolah, guru PJOK di SMP N 1 Palembang yang telah membantu dalalm peneltian ini, serta rekan-rekan sejawat yang telah membantu dalam pelaksanaan penelitian ini. 